\title{
Sexual Harassment in the Workplace: An Exploratory Study from Lebanon
}

\author{
Hussin Jose Hejase \\ Dean of Faculty of Business and Economics \\ American University of Science and Technology \\ Beirut, Lebanon \\ E-mail: hhejase@aust.edu.lb
}

Received: Jan.13, 2015 Accepted: Jan. 29, 2015 Published: January 29, 2015

doi:10.5296/jmr.v7i1.6965

URL: http://dx.doi.org/10.5296/jmr.v7i1.6965

\begin{abstract}
Sexual harassment is a recurring problem around the globe. Different nations have taken measures to deal with the consequences of such a problem. Continuous development of policies is observed. Nations or companies are dealing with the topic by either reacting or pro-acting to the salient situations. Lebanon is not different than other countries. Sexual harassment occurs in the workplace, but unfortunately there are no public records of the cases. Therefore, this research attempts to close such a gap. This paper explores sexual harassment in the workplace within selected Lebanese organizations. A questionnaire has been developed and circulated to that purpose. The organizations contacted comprised of one hotel, several restaurants and night clubs, and a university. The high response rate $(67 \%)$ has enabled a comprehensive and reliable information resource to be created, hopefully to enable application in terms of on-the-ground practice and levels of awareness and action in the stated regions. This information is considered particularly timely as it reflects the current position in Lebanon. The expected outcome of this paper is the development of policies and creation of awareness which build on the findings of this research. Findings are also expected to contribute to defining future research work.
\end{abstract}

Keywords: Harassment at work, sexual harassment, Lebanon 


\section{Introduction}

The Beijing Platform for Action (PFA), which was adopted at the United Nations Fourth World Conference on Women, in Beijing, in 1995, calls on governments, the international community, and civil society to take strategic action in twelve critical areas of concern, including the area of violence against women: specifically, the prevention of sexual harassment in the workplace (McGolgan, 2004).

Harassment and sexual harassment are recognized as a form of discrimination on the grounds of sex and, thus, are contrary to the principle of equal treatment between men and women (Numhauser-Henning \& Laulom, 2012). According to the U.S. Equal Employment Opportunity Commission (EEOC, 2011a), "Harassment" is defined as "unwelcome conduct that is based on race, color, religion, sex (including pregnancy), national origin, age (40 or older), disability or genetic information. Harassment becomes unlawful where 1) enduring the offensive conduct becomes a condition of continued employment, or 2) the conduct is severe or pervasive enough to create a work environment that a reasonable person would consider intimidating, hostile, or abusive. An unwanted conduct related to the sex of a person occurs with the purpose or effect of violating the dignity of a person, and of creating an intimidating, hostile, degrading, humiliating or offensive environment" (Para 2). While, "Sexual harassment" is defined as "unwelcome sexual advances, requests for sexual favors, and other verbal or physical conduct of a sexual nature" that interferes with one's employment or work performance or creates a "hostile or offensive work environment" (EEOC, 2011b, Para 1-2). Another definition for sexual harassment is "where any form of unwanted verbal, non-verbal or physical conduct of a sexual nature occurs, with the purpose or effect of violating the dignity of a person, in particular when creating an intimidating, hostile, degrading, humiliating or offensive environment" (McGolgan, 2004).

Though the definition of sexual harassment is clear and many research work has been performed, yet "in the absence of rigorous qualitative and longitudinal designs, the

dynamics of gender, power, and harassment remain poorly understood" (McLaughlin, Uggen, and Blackstone (2012, p. 1). Furthermore, sexual harassment is not given any importance in the Lebanese and most of the Gulf Cooperation Council (GCC) countries' environments (Gatten, 2012; Bajracharya and Sijapati, 2012); this creates a problem since the equality of men and women at work is a prominent issue today; a fact that has motivated the researcher to study the current work environment in Lebanon as to how it deals with sexual harassment. Several sectors and organization share the same common problem of "Sexual Harassment", especially in the night life industry or night clubs and restaurants, industries and several other environments.

The expected results and findings shall be used to facilitate the evaluation process of sexual harassment; consequently, indicators have to be developed in relation to women at work. As a result, the designed questionnaire was targeted at national-level business organizations, banks and night life industries for both employers and employees. 


\section{Literature Review}

Sexual harassment is a violation of the American Title VII of the Civil Rights Act of 1964; it is against the workplace policy for any employee, male or female, to sexually harass other employees by

- Making unwelcome sexual advances, requests for sexual favors or other verbal or physical conduct of a sexual nature a condition of an employee's employment; or

- Making submission to or rejection of such conduct the basis for employment decisions that affect the employee; or,

- Creating an intimidating, hostile or offensive working environment by such a conduct (USAjobs.g4s.com, 2012).

Thus, as a definition, sexual harassment is an unwelcome attention of a sexual nature that makes a person feel uncomfortable. It includes a range of behaviors from mild transgressions and annoyances to serious abuses, which can involve forced sexual activity. Sexual harassment is considered as a form of illegal discrimination as well as a type of psychological and sexual abuse (El Shimi, 2011; ILO, 2010, p. 7).

To be sexually harassed is to be the victim of any situation stated in the aforementioned definitions. Each organization and/or each community has its own socio-cultural agenda whereby the terms and conditions show what can be considered as sexual harassment. For instance, in Lebanon, any word or expression of a speech from an opposite sex that is aggressively said is not yet considered as sexual harassment (Shaheen, 2013, Para 22). The sexually harassed can be anyone, male or female, whether a supervisor, a client, a co-worker (EEOC, 2011b), teacher or professor, a student SAPAC (n.d.), a friend and even a stranger.

As for the harasser, he/she does not have to be of the opposite sex; he/she may be completely unaware that his/her behavior is offensive or constitutes sexual harassment, or is perhaps completely unaware that his/her actions could be unlawful. The sexual harassers choose their victims based on characteristics such as, age, perceived passivity, lack of assertiveness, poor education, low self-esteem and other areas of vulnerability (Sexual Harassment Prevention Institute, 2012, Para 5).

For Britz, Elmarie (2007, November) as stated in The Perceptions of Employees Regarding Sexual Harassment in an Administrative Higher Educational Work Environment. (Magister Short Dissertation), Business Administration, Johannesburg, South Africa, sexual harassment may take different forms. According to Britz (2007), several forms of sexual harassment exist, namely:

- Verbal - Sexual innuendoes, suggestive comments, jokes of a sexual nature, sexual propositions or sexual threats.

- Non-Verbal - Sexual suggestive objects or pictures, graphic commentaries, suggestive or insulting sounds, leering, whistling or obscene gestures. 
- Physical - Unwanted physical contact, including touching, pinching, brushing the body, coerced sexual intercourse or assault (p. 16).

Furthermore, to understand sexual harassment, it is necessary to shed light on the two basic forms of sexual harassment, namely, Quid Pro Quo and Hostile Work Environment (Mondy and Mondy, 2012, p. 93). Quid Pro Quo sexual harassment usually occurs when a harasser asks or forces an employee to perform sexual favors to keep a job, receive a promotion, receive a raise, obtain some other work-related opportunities, or avoid receiving negative consequences such as demotion or dismissal. Whereas, Hostile Work Environment sexual harassment occurs when organizational members are faced with an intimidating, hostile, or offensive work environment because of their sex (Jones \& George, 2011, p. 181).

Robbins and Coulter (2011) contend that sexual harassment is not a problem in one country; "It is a global issue. For instance, the European Commission found that 30 to 50 percent of female employees in European Union countries had experienced some form of sexual harassment. Moreover, sexual harassment cases have been filed against employers in countries such as Japan, Australia, New Zealand, and Mexico" (p. 357). According to Mondy and Mondy (2012), "the US Equal Employment Opportunity Commission fielded more than 13,867 charges of sexual harassment. From 1990 to 2009, the percentage of sexual harassment claims; files by male employees has doubled from 8 to $16 \%$. Awards to charging parties amounted to more than $\$ 47.4$ million, not counting monetary benefits obtained through litigation" (p. 93). In Egypt, 83 percent of Egyptian women and 98 percent of foreign women have been sexually harassed, but only 2 percent have reported it (El Shimi, 2011). Saghieh, a Lebanese Human Rights lawyer, cited by Gatten (2012), has looked for cases where sexual harassment has been brought before employment tribunals. "So far, he has not found a single case of recorded sexual harassment, but says tribunal judges often report hearing testimony of incidents during unfair dismissal cases, which is never written down" (Para 11). Therefore, although there are scarce statistics about the subject, the Lebanese Ministry of Social Affairs revealed in 2007 that three complaints had been filed per week for sexual harassment and rape (Thomas, 2013, p. 210).

Beside the huge amounts of financial losses, sexual harassment has many implications both on individuals and organizations alike. Exhibit 1 shows a summary of such implications on organizations; while Exhibit 2 shows implications on individuals.

Exhibit 1. Implications on organizations

- It decreases productivity and increases team conflict.

- Decreases success and meeting of financial goals

- Decreases job satisfaction

- Sexual Harassment per missal can undermine ethical standards and discipline in the organization which will lead to disrespect and trust among employees and their seniors.

- The image of the organization will suffer financially, and reputation-wise when complainants take the issue to court.

- Increases loss and absenteeism of staff members and expertise. 
Source: Boland, 2002.

Exhibit 2. Implications on individuals

- Decrease in work and/or school performance

- Loss of career and income; dropping out of school

- Personal life has been exposed to public viewers which could lead to depression, anxiety, shame and guilt and loss of motivation.

- Humiliation and objectified by gossip and scrutiny

- Loss of trust in the environment and people

- Extreme stress upon relationship with others

- Being discriminated from a work place or school

- Re-location to another surrounding

- Loss of references and recommendations

Source: Boland, 2002.

\subsection{Prevention of Sexual Harassment}

According to the Australian Human Rights Commission (2008), “every employer, regardless of size, must take all reasonable steps to prevent sexual harassment in the workplace to avoid liability. This means that employers must actively implement precautionary measures to minimize the risk of sexual harassment occurring and to respond appropriately when harassment does occur" (p. 21). In short, there are two main actions that employers must take to avoid liability for sexual harassment:

1. Take all reasonable steps to prevent sexual harassment from occurring.

2. If sexual harassment does occur, take appropriate remedial action.

To prevent sexual harassment, an employer should have a sexual harassment policy, implement it as fully as possible, and monitor its effectiveness. Moreover, in order to remedy sexual harassment, an employer should have appropriate procedures set up for dealing with complaints once they are made (ibid). A similar approach is also recommended by Jones and George (2007), whereby, they identified the steps managers can take to eradicate sexual harassment. Exhibit 3 depicts such steps.

Exhibit 3. Steps to eradicate sexual harassment

1. Develop and clearly communicate a sexual harassment policy endorsed by top management.

2. Use a fair complaint procedure to investigate charges of sexual harassment.

3. When it has been determined that sexual harassment has taken place, take corrective actions as soon as possible.

4. Provide sexual harassment education and training to organizational members, including managers. 
According to USAjobs.g4s.com (2012), "Employees who believe they are the victims of sexual harassment and/or workplace harassment are to immediately contact their supervisor, a manager, the undersigned, or the Corporate Human Resources Department for appropriate action. For the comfort of the employee complaining of sexual harassment, upon request, a management representative who is the same gender as the employee will be made available to receive the complaint. Complaints will be investigated in a timely and thorough manner, and will be kept confidential to the extent practicable within the context of an investigation" (USAjobs.g4s.com, 2012).

In the event the investigation reveals that sexual harassment, discrimination, or

other inappropriate or unprofessional conduct (even if not unlawful) has occurred, further action is to be taken, including disciplinary action, such as, but not limited to, reprimand, change in work assignment, loss of privileges, mandatory training or suspension and/or immediate termination (Wellesley.edu, n.d., Para 32).

\section{Methodology}

This is an exploratory research that aims to assess a conveniently selected sample of Lebanese employees' and employers' awareness of the topic of sexual harassment at work. Such data is necessary to support the development and design of sexual harassment policies in the different work areas in order to minimize stress and unhealthy work environment conditions that may result from such abuse.

For the aforementioned purpose, a survey questionnaire has been designed, making sure that "research questions encapsulate what the researcher is trying to find and provide the direction and shape of the research" (Hammond and Wellington, 2013, p. 127). Moreover, according to Hejase \& Hejase (2013), "questionnaires are popular, low cost, and convenient (p. 187). However, Phillips \& Stawarski (2008) contend that the challenge is to continuously improve the way questionnaires are worded (p. 137).

Accordingly, the survey tool is a structured questionnaire divided into four parts. The first part is composed of eight demographic questions about the sample such as age, gender, marriage status, location of living, educational degree earned, email address, job title, and attachment to religion. The second part is composed of twelve questions regarding habits and knowledge about sexual harassment. The third section deals with personal experience of sexual harassment, and finally the fourth section deals with actions taken against sexual harassment.

Respondents were chosen based on their willingness to participate and answer the set questionnaire. They belong to several organizations, including, universities, hotels, banks, and night-life industries (Restaurants, night clubs, and bars). The survey questionnaire was distributed to 150 individuals. However, a total of 100 respondents did effectively fill up the questionnaires; the remaining were classified as useless, whereby, 25 questionnaires were half full, 12 questionnaires were haphazardly filled, and the remaining 13 questionnaires only had demographics. Then, the response rate is $66.67 \%$. 
It is worth mentioning that the questionnaire was piloted by a number of relevant organizations. An analysis of responses and reviewers' comments was conducted to justify the validity of the questionnaire. Based on the outcome, a revised version of the questionnaire was produced.

\section{Results and Findings}

Filled questionnaires were sorted and coded. Data analysis was performed using SPSS (Statistical Product and Service Solutions, an IBM product acquired by IBM in 2009 (Hejase and Hejase, 2013, p. 58). Data was generated using descriptive statistics, where data is sorted, categorized, and evaluated using frequency and probability distribution tables as well as cross-tabulations.

Results show that $57 \%$ of the respondents are males, whereas $43 \%$ are females. The average age is 27 years for both genders. $57 \%$ of the respondents earned their BA/BS degrees, $21 \%$ has $\mathrm{MA} / \mathrm{MS} / \mathrm{MBA}$ degrees, $7 \%$ has a $\mathrm{PhD}$ degree and the remaining respondents have vocational and high school education. The majority of the respondents or $66 \%(36 \%$ males and 30\% females) are still living with their parents, $24 \%$ are living with friends (15\% males and $9 \%$ females), and only $10 \%$ live alone ( $6 \%$ males and $4 \%$ females). The great majority of the respondents or $78 \%$ are employees, $15 \%$ are managers, and $8 \%$ are owners of businesses.

\subsection{Personal Habits}

Respondents, on the average, reflect through their responses that they are outgoing with $79 \%$ participating in night activities (50\% males and 29\% females), and $71 \%$ do not mind that their friends have drinks (42\% males and 29\% females). However, $88 \%$ of the respondents abide by their families' values (50\% males and 38\% females), and $87 \%$ declared that faith plays an important role in their lives (51\% males and 36\% females). Furthermore, 63\% follow the fashion fad (30\% males and 33\% females), and $43 \%$ have no restrictions as to their habits (28\% males and $15 \%$ females).

Results also show that males, who constitute $57 \%$ of the sample, are divided in such a way that $26 \%$ have a male supervisor, and $31 \%$ have a female supervisor. Also, the females, who constitute $43 \%$ of the sample, are divided in such a way that $31 \%$ have a male supervisor, and $12 \%$ have a female supervisor. In general, there are $57 \%$ male supervisors versus $43 \%$ female supervisors.

\subsection{Work Formality}

Respondents in their majority (varying between 67 to $73 \%$ ) claim that their organizations' cultures are formal.

\subsection{Promotions Criteria}

Organizations are professional in their promotions' criteria since $80 \%$ of the respondents of both genders claim that performance standards are the main criterion for promotions on the job. Moreover, $48 \%$ of the respondents believe that the relationship with the supervisor or manager is a criterion for promotion, and $29 \%$ of the respondents agree that the appearance is 
also a criterion for promotion.

\subsection{Definition of Sexual Harassment}

Respondents prefer to recognize sexual harassment as physical interference (85\%) which includes touching, rubbing or invading the personal space of the other. More descriptions include asking for sexual favors (67\%), exposing sexual material (59\%), and using verbal remarks (48\%). It is also interesting to note that sexual jokes and prolonged staring came at the bottom of the list with $33 \%$ and 32\%, respectively. These last two descriptions are typical activities practiced by Middle Eastern persons of both genders and usually are not considered offensive.

\subsection{Consequences of Sexual Harassment}

When respondents were asked about their feelings toward sexual harassment's consequences in point of view of the harassed, they responded, in their majority, by saying that it is dangerous (71\%) and annoying. Moreover, 37\% commented that sexual harassment is embarrassing (37\%), 5\% said it is casual, and 12\% declared that it is not a big issue.

\subsection{Experiencing Sexual Harassment}

A total of $28 \%$ ( $12 \%$ of the male respondents and $16 \%$ of the female respondents) were sexually harassed. However, $9 \%$ of the males and $12 \%$ of the females were sexually harassed at work. The surprising outcome is that only $5 \%$ of the cases were reported.

\subsection{Sexual Harassment Impact}

Respondents who were subject to sexual harassment felt mainly insulted, had low self esteem, and surprisingly $7 \%$ claim that they were not affected. Possibly these 7 persons did not report their cases.

\subsection{Reaction to Sexual Harassment}

Only $7 \%$ of the harassed respondents (males and females) have taken action. However, section 4.6, previously discussed, indicate that $5 \%$ of the cases were reported at work.

One may conclude from the above outcomes that 5 respondents out of 28 respondents who had experienced harassment were ready to act on it. One possible explanation is that the subject of sexual harassment is considered as a taboo in the Lebanese culture, and the offended may feel more pressure from the community if declared openly. Another possible reason is that though the Lebanese Government does have an official law concerning sexual harassment, but it rather deals with very serious cases of rape.

\subsection{Reasons Incident Were not Reported}


Table 1. Reaction to Sexual Harassment

\begin{tabular}{|l|l|l|l|}
\hline Reaction to Sexual Harassment & Male, \% & Female, \% & Total, $\%$ \\
\hline Fear of not being taken seriously & 03 & 01 & $\mathbf{0 4}$ \\
Fear of not being promoted & 02 & 03 & $\mathbf{0 5}$ \\
Fear of being fired from the job & 01 & 01 & $\mathbf{0 2}$ \\
Fear of receiving a warning & 01 & 02 & $\mathbf{0 3}$ \\
Out of shame & 00 & 02 & $\mathbf{0 2}$ \\
Total & $\mathbf{0 7}$ & $\mathbf{0 9}$ & $\mathbf{1 6}$ \\
\hline
\end{tabular}

Table 1 shows that several reasons were given by those harassed respondents for not reporting their cases. The most salient reasons are: fear of not being taken seriously, fear of not being promoted, fear of receiving a warning and kept in record, fear of being fired from the job, and out of shame (only females).

When respondents were asked if any action was taken by their supervisors to whom the incidents were reported, all of them answered with an affirmative response.

\subsection{Personal Preferences}

Several personal aspects of the respondents' life styles that might have played a role in inducing a type of sexual harassment were identified. Both genders wear attractive outfits $(35 \%)$ and wear strong perfume (40\%); however, $67 \%$ believe that physical appearance is important at work, and $90 \%$ of the respondents believe that physical appearance impacts the behavior of the other towards them. It is worth noting that $44 \%$ of the respondents, $30 \%$ males and $14 \%$ females, agree that they may use any means to get ahead in the organization.

\subsection{Attitude towards Sexual Harassment}

Table 2. Attitude towards Sexual Harassment

\begin{tabular}{|l|l|l|l|}
\hline Attitude Towards Sexual Harassment & Male, \% & Female, \% & Total, \% \\
\hline $\begin{array}{l}\text { Do you know of anyone in your immediate circle of } \\
\text { friends who has been sexually harassed? }\end{array}$ & 27 & 23 & \\
Yes & 30 & 20 & $\mathbf{5 0}$ \\
No & & & $\mathbf{5 0}$ \\
Have you ever quit work because of sexual harassment? & 00 & 01 & \\
Yes & 57 & 42 & $\mathbf{0 1}$ \\
No & & & \\
Have you asked to be transferred to another department / & 04 & 00 & $\mathbf{0 4}$ \\
branch because of sexual harassment? & 53 & 43 & $\mathbf{9 6}$ \\
Yes & & & \\
No & & & \\
If any incident of sexual harassment occurs, who & $\mathbf{2 8}$ & $\mathbf{2 5}$ & $\mathbf{5 3}$ \\
would you blame? & $\mathbf{0 5}$ & $\mathbf{0 4}$ & $\mathbf{0 9}$ \\
The Harasser & $\mathbf{1 9}$ & $\mathbf{1 4}$ & $\mathbf{3 3}$ \\
The Harassed & $\mathbf{0 5}$ & $\mathbf{0 0}$ & $\mathbf{0 5}$ \\
Both the Harasser and the Harassed & & & \\
None of them & &
\end{tabular}


Table 2 shows that $50 \%$ of the respondents know somebody in their immediate circle who has been harassed. Only 1 female out of 3 who had reported the incident quit her job, and 4 males asked to be transferred to another department / branch.

When respondents were asked who to be blamed for the sexual harassment incident if it happens, 53\% blamed the harasser, 9\% blamed the harassed, 33\% blamed both the harassed and harasser, and $5 \%$ blamed no body.

However, when respondents were asked if they are ready to prosecute the Harasser in the court of law if it happens to them, only 53\% (26\% males and $27 \%$ females) of the respondents stated that they are ready to go to the court of law in case they are sexually harassed. This question shows that respondents do not trust the Lebanese legal system in this respect, and also know that they will be highly affected socially if the cases become public. However, the respondents who were ready to go to court said that they want the harasser to be "punished". Moreover, $84 \%$ (44\% males and 40\% females) of the respondents agree that organizations should have policies to prevent sexual harassment at work. The same percentage agreed that it is the organizations' obligation to implement measures assuring the creation of a sexual harassment free environment. Finally, 73\% (34\% males and 39\% females) of the respondents are ready to get training or education about the topic of sexual harassment.

\section{Conclusion and Implications}

Sexual harassment is considered one of the most important issues that might negatively affect an organizational environment; consequently, this research has been carried out in an attempt to minimize, if not eradicate, this effect. This paper explores sexual harassment in the workplace within selected Lebanese organizations. Results show that $28 \%$ of the respondents have experienced/ have been exposed to sexual harassment.

The harasser might be a male or female, and it is not necessary to be from the opposite sex. In the United States, the Civil Rights Act of 1991 has given individuals, especially employees, the means to fight sexual harassment. It is believed that once a taboo subject, in this case sexual harassment, is out in the open, fewer victims would be willing to suffer in silence. In 1994, the Equal Employment Opportunity Commission received 14,420 sexual harassment claims, up from 5,623 cases in 1989. Still, about 90\% of the cases are never reported. According to a recent poll by the Society for Human Resource Management, 63\% of the companies surveyed view sexual harassment as a real problem. Three-quarters of them offer training programs, and $97 \%$ have instituted written policies on sexual harassment.

Yet, and according to the results that have been obtained in this current research, sexual harassment is considered to be a hot zone where the harassed still consider it a taboo. This is due to social environment, culture, norms, and values.

There is only limited evidence of the existence of Codes of Practice dealing with the issue of sexual harassment in Lebanon, especially since the legislation upon which courts are based does not explicitly define sexual harassment.

There is also a very low level of apparent coverage of the issue of sexual harassment / 
harassment based on sex in the aforementioned Codes of Practice to which the responding organizations were party, indicating perhaps, that the specific issue of sexual harassment has not yet achieved a high level of priority within the context of collective bargaining.

\section{Recommendations}

After asking several Lebanese lawyers about sexual harassment, they all agreed that the various legal systems appear to adopt a fairly broad approach to employer liability; generally where employers are legally liable for sexual harassment/ harassment based on evidenced sexual acts like rape.

There is little consistency of practice across the respondents in relation to - for example - the bodies to which complaints of work-related sexual harassment may be brought, the support mechanisms available to complainants, or the remedies for sexual harassment. Most of the respondents' organizations does have measures in place to protect sexual harassment victims from being victimized, and also provide compensation to the victim.

The diversity of responses to questions in relation to the issue of legal complaints and remedies is not surprising, as the systems governing the enforcement of employment rights generally vary widely across the participating organizations.

There is a general absence of specific grievance procedures and sanctions for sexual

harassment / harassment based on sex. Where such procedures do exist they appear to depend on the nature of the harassment.

Preventing sexual harassment from occurring is much less disruptive, much less expensive, and much less time consuming as compared to the time spent by supervisors investigating and litigating case-by-case incidents, doing their best to prevent sexual harassment from occurring. Therefore, prevention is the best tool for the elimination of sexual harassment. That's why the supervisor or the manager needs to have some basic education in a number of employee-relations issues, including sexual harassment. As with supervisors and managers, all others should also receive information about sexual harassment. For employees, as a whole, the emphasis should be on expectations for interpersonal behavior rather than on legal and management issues.

It might be more important for employees to solve sexual harassment problems in-house, avoiding law suits if possible. Many organizations have established anti-harassment policies and employee-education programs. The Australian Human Rights Commission (2008) contends that effective harassment prevention programs include:

- $\quad$ issuing a specific policy prohibiting sexual harassment,

- developing a complaint procedure employees can follow,

- $\quad$ creating a work atmosphere that encourages sexually harassed staff to come forward, and 
- $\quad$ investigating and resolving complaints immediately, and taking disciplinary actions against harassers (pp. 22-23).

\section{Limitations}

The current research is considered one component of a wider research that deals with assessment of the aggressive working conditions dealing with violence against women in particular and against men and women in general. The former would appear to be an effective approach that enables cross referencing with other variables such as occupational type and sector. However, such an approach would not necessarily be capable of filling some of the research gaps highlighted by the respondents participating in the current research i.e. results of legal proceedings, psycho-social effects of sexual harassment. Another feature of the research is that a number of the dedicated research studies that have been undertaken have focused on the working conditions of women or, as aforementioned, on the issue of violence against women and there may therefore be, an under-representation in the research literature on the level and nature of male sexual harassment.

There is only limited evidence that the research that is being conducted is being used to influence policy / practice on the issue.

It is clear that significant research gaps remain in relation to the incidence and nature of harassment, the profile of the harasser and the victim, profile of the organization, judicial outcomes etc... This is the basic data requirement necessary to describe the issue and facilitate inter country-comparisons. However, there is also a requirement for research in other areas which would address such issues as the impact of sexual harassment, the link between sexual harassment and sick leave / absenteeism and the victim's alienation from the labor market.

The results of this study have implications for staff and managers in organizations. The relationship that has been proved to exist between prevention, trust, management's support, culture and a harassment free work environment, indicates the importance of such factors as prerequisites of the success of creating sexual harassment free institution.

The current paper serves as an eye opener to researchers who are interested in studying sexual harassment in a Middle Eastern country and at the same time study the case where government does not have a clear policy or regulation about harassment in its formal legal system. Moreover, this paper emphasizes the fact that universities and other institutions of higher education hold the responsibility to create awareness of sexual harassment to enable their students to survive the existing hostile and difficult market's conditions, and at the same time, be ready to face hostile situations with responsibility and ethical behavior. Finally, this paper contributes and adds value to the literature, characterized as highly lacking, of the current Lebanese job-market.

\section{Future Research}

A variety of preventative initiatives should be undertaken by both governmental organizations and the social partners. However, the general lack of research on sexual 
harassment may imply that such preventative measures are not always grounded in research.

Basically, preventative initiatives are related to awareness raising and training, with several references being made to brochures, guidelines, articles, etc... Awareness raising and training initiatives are primarily focused on employers, managers and trade union officials. Specific initiatives that also target employees are only referenced in a limited number of responses.

The roles and responsibilities of employers, trade unions, managers and employees with respect to preventative initiatives should be described further in specific terms. Employers are seen to have a role in awareness raising and prevention and ensuring that the working environment is free of harassment; their role in developing policy statements and ensuring that these are implemented at every level is less evident. The Australian Human Rights Commission (2008) recommends that although "The Sex Discrimination Act does not prescribe any particular type of procedure, so employers have the flexibility to design a system that suits the organization's size, structure and resources" (p. 32). Therefore, a research should be undertaken to see what rules are best to be implemented.

\section{Acknowledgement}

The author would like to acknowledge the constructive criticism and editing performed by Mrs. Henriette Skaff, senior editor at AUST ${ }^{\text {ee }}$ P Publications Department.

\section{References}

Australian Human Rights Commission. (2008). Effectively preventing and responding to sexual harassment: A Code of Practice for Employers (eight ed.). Retrieved November 20, 2014 , from https://www.humanrights.gov.au/sites/default/files/content/sexualharassment/employers_code /COP2008.pdf

Bajracharya, R., \& Sijapati, B. (2012, March). The Kafala System and Its Implications for Nepali Domestic Workers. Policy Brief, No 1, 1-16. Centre for the Study of Labour and Mobility (CESLAM). Retrieved October 16, 2014, from http://www.ceslam.org/docs/publicationManagement/Kafala_Nepali_Domestic_Workers_Fe male_Migration_Eng.pdf

Boland, M.L. (2002). Sexual harassment: Your guide to legal action. Naperville, IL: Sphinx Publishing.

Britz, E. (2007, November). The Perceptions of Employees Regarding Sexual Harassment in an Administrative Higher Educational Work Environment. (Magister Short Dissertation), Business Administration, Johannesburg, South Africa.

Gatten, E. (2012, May 8). Sexual harassment rife in workplaces. The Daily Star. Retrieved October 16, 2014, from http://www.dailystar.com.lb/News/Local-News/2012/May-08/172647-sexual-harassment-rife -in-workplaces.ashx\#axzz3GJvHAGzJ

Hammond, M. \& Wellington, J. (2013). Research Methods: The Key Concepts. Abingdon, 
Oxon: Routledge.

Hejase, A.J. \& Hejase, H. J. (2013). Research Methods, A Practical Approach for Business Students (second ed.), Philadelphia: Massadir Inc.

International Labour Organization-ILO. (2010, December). Guide on Prevention of Sexual Harassment in the Workplace. Beijing Zhongze Women's Legal Consultation and Service Center - Women Watch, China. Retrieved October 16, 2014, from http://www.ilo.org/wcmsp5/groups/public/---asia/---ro-bangkok/---ilo-beijing/documents/publ ication/wcms_157626.pdf

Jones, G.R., \& George, J.M. (2007). Contemporary Management (fifth ed.), McGraw-Hill Higher Education.

Jones, G.M., \& George, M. J. (2011). Contemporary Management (seventh ed.). New York, NY: The McGraw-Hill Companies.

Kuter, U., \& Yilmaz, C. (2001). Survey methods: Questionnaires and Interviews. Retrieved January 24, 2015, from http://lte-projects.umd.edu/charm/survey.html

Malhotra, K.N. (2002). Basic Marketing Research: Applications to Contemporary Issues. New Jersey: Pearson Education Inc. / Prentice Hall.

McGolgan, A. (2004, June). Report on Sexual Harassment in the Workplace in EU Member States, The Irish Presidency of the European Union in association with Farrell Grant Sparks Consulting. Dublin: Department of Justice, Equality and Law Reform.

McLaughlin, H., Uggen, C. \& Blackstone, A. (2012). Sexual Harassment, Workplace Authority, and the Paradox of Power. American Sociological Review, $X X(\mathrm{X}), 1-23$. http://dx.doi.org/10.1177/0003122412451728

Mondy, R.W., \& Mondy, J.B. (2012). Human Resource Management (twelfth ed.). Edinburgh Gate, Essex, UK: Pearson.

Numhauser-Henning, A. \& Laulom, S. (2012). Harassment related to Sex and Sexual Harassment Law in 33 European Countries. European Network of Legal Experts in the Field of Gender Equality: Discrimination versus Dignity. European Union.

Roberts, B.S., \& Mann, R.A. (1994). Sexual Harassment in the Workplace, The University of Akron. Retrieved March 13, 2014, from http://www3.uakron.edu/lawrev/robert1.html

Sexual Assault Prevention \& Awareness Center - SAPAC (n.d.). What is Sexual Harassment? Retrieved October 16, 2014, from http://sapac.umich.edu/article/63

Sexual Harassment Prevention Institute. (2012). Sexual harassment training Patterns-Personalities and Types of Harassment. Retrieved October 13, 2014, from http://www.sexualharassmenttraining.biz/sexual_harassment_training_Patterns-Personalitiesand-Types-of-Harassment.html

Shaheen, K. (2013, November 4). Taking a stand over sexual harassment. The Daily Star. 
http://www.dailystar.com.lb/News/Lebanon-News/2013/Nov-04/236747-taking-a-stand-oversexual-harassment.ashx\#axzz3GJvHAGzJ

The US Equal Employment Opportunity Commission (EEOC). (2011a). Harassment. Washington, D.C. Equal Employment Opportunity Commission. Retrieved October 13, 2014, from http://www.eeoc.gov/laws/types/harassment.cfm

The US Equal Employment Opportunity Commission (EEOC). (2011b). Sexual Harassment. Washington, D.C. Equal Employment Opportunity Commission. Retrieved October 13, 2014, from http://www.eeoc.gov/laws/types/sexual_harassment.cfm

Thomas, M.C. (2013). Women in Lebanon: Living with Christianity, Islam, and Multiculturalism. New York, NY: Palgrave MacMillan

USAjobs.g4s.com. (2012). Sexual Harassment and Workplace Harassment Policy. Retrieved October 14, 2014, from http://usajobs.g4s.com/files/2012/04/Sexual-Harassment-and-Workplace-Harassment-Policy. pdf

Wellesley.edu. (n.d.). Policy Against Sexual Harassment and Other Unlawful Discrimination, Harassment, and Retaliation. Retrieved September 10, 2014, from http://www.wellesley.edu/sites/default/files/assets/departments/humanresources/files/policies/ policy_against_sexual_harassment_and_other_unlawful_discrimination_0919013.pdf 